\title{
Effects of Combustion Improver on Performance and Emission Characteristics in Multicylinder Diesel Engine
}

\author{
V.Saravanan, M. Nitish Kumar S. Gowthaman, P.Manikandan,
}

\begin{abstract}
The goal of the existing investigation is to research the impacts of the minor enlargement of benzyl liquor, classified one at a time as aliphatic and fragrant sort alcohols depending on the classified hydroxyl collecting function in their sub-atomic shape. Lemon grass and diesel mixtures (B25 and B50) had been organized and attempted to take a look at the CI engine execution, discharge and burning attributes under zero burden conditions. To each one of the four mix gasoline checks organized for B25 and B50, benzyl liquor introduced substances were included at $1 \%$ - 5\% fixations with the aid of quantity. Test assessments for the general public of the diverse powers had been accomplished in a multi chamber, 4-stroke and regular pace CI motor and the motor attributes have been contrasted and diesel and bio gas mixes. The exploratory exam uncovers that the bad execution of B25 and B50 is upgraded with benzyl liquor (Bn) growth. The development in execution is substantial with an expansion in the centralizations of liquor in B25 and B50 mixes. Higher $\mathrm{HC}, \mathrm{CO}$ and smoke outflows related with $B 25$ and B50 mix fills emanations are dwindled with liquor compulsion. The end result of this exploration paintings is that poor burning attributes of the bio gas- diesel mix may be progressed with the minor enlargement of aliphatic and aromatic liquor. Higher NOx emanations, benzyl liquor verified promising outcomes as a long way as execution parameters like productiveness, discharge and ignition improvement.
\end{abstract}

Keywords: multicylinder diesel engine, bio diesel, alcoholic additives, Combustion characteristics, emission

\section{INTRODUCTION}

$\mathrm{M}$ ostly diesel engine emits polluted harmful gases to environment due to in-complete combustion. When incomplete combustion acts on a diesel engine, it creates soot, $\mathrm{NOx}, \mathrm{HC}, \mathrm{CO}$ emissions. These are some of harmful gaseous which are emitted by in-complete combustion process. Fuel

Revised Manuscript Received on December 05, 2019.

* Correspondence Author

V. Saravanan, UG Student, Department of Automobile Engineering Kalasalingam Academic of Research and Education, Krishnankoil, Srivilliputtur, Tamilnadu, India-626126, Email: manikandanauto6707@gmail.com

S. Nitish Kumar, UG Student, Department of Automobile Engineering Kalasalingam Academic of Research and Education, Krishnankoil, Srivilliputtur, Tamilnadu, India-626126, Email: subaraja006@gmail.com

S. Gowthaman *, Associate professor, Department of Automobile Engineering Kalasalingam Academic of Research and Education, Krishnankoil, Srivilliputtur, Tamilnadu, India-626126, Email: gowthaman.s@klu.ac.in

P. Manikandan, UG Student, Department of Automobile Engineering Kalasalingam Academic of Research and Education, Krishnankoil, Srivilliputtur, Tamilnadu, India-626126, Email: samblessing8@gmail.com additives and oxygen improved additives are the effective methods to reduce the emission and also it favourse to increase the performance of the engine. This in- complete combustion process occurs due to lag of oxygen and poor quality of cetane number in fuel at the combustion chamber, if the level of the oxygen and cetane quality improves then the performance of the engine can improved and rate of emission can reduced as compare to the base fuel. This study, investigated the effect of additives such as n-pentanol and benzyl alcohol on performance and emission characteristics of multi cylinder engine. These type of additives are alcoholic based addictive which has high calorific value it helps for good thermal efficiency and easily vaporize the fuel mixture, also the oxygen content in addictive will help the fuel mixture for complete combustion. Through this the emission from the period of after combustion will be get reduced compare to base fuel combustion.

In this process the additives cannot be mixed directly to the fuel and used in the engine. They need to blend and converted into biodiesel, so here we use vegetable oil or feed stock oil to blend the diesel. In this work we are going to blend the diesel with oil with different ratios and $5-10 \%$ of additive is to be added in the fuel. These different mixtures are going to be tested in the multi- cylinder diesel engine. On this the performance test and emission test are going to be plotted using systematic sensors, each of the test will be compared with the previous results. Through this the correct ratio is going to found for reducing emission and to increase the performance of the CI engine.

\section{EXPERIMENTAL PROCEDURE}

Figure 1 shows the multi cylinder diesel engine with hydraulic dynamometer. It is placed over a testing rail bed with open jacket water cooling system. . In other side they consist of rpm regulator with digital rpm meter to set an accurate rpm for testing. Fuel supply set up is slightly changed, due to measure the fuel consumption for $10 \mathrm{cc}$. So they place a glass tube consist of reading which shows the cc of fuel consumption. In exhaust a thermo sensor is placed to detect the temperature of exhaust gas while the engine is running. This engine has open jacket cooling system which is cheaper than the other cooling system they also maintain the temperature of the engine as low. 


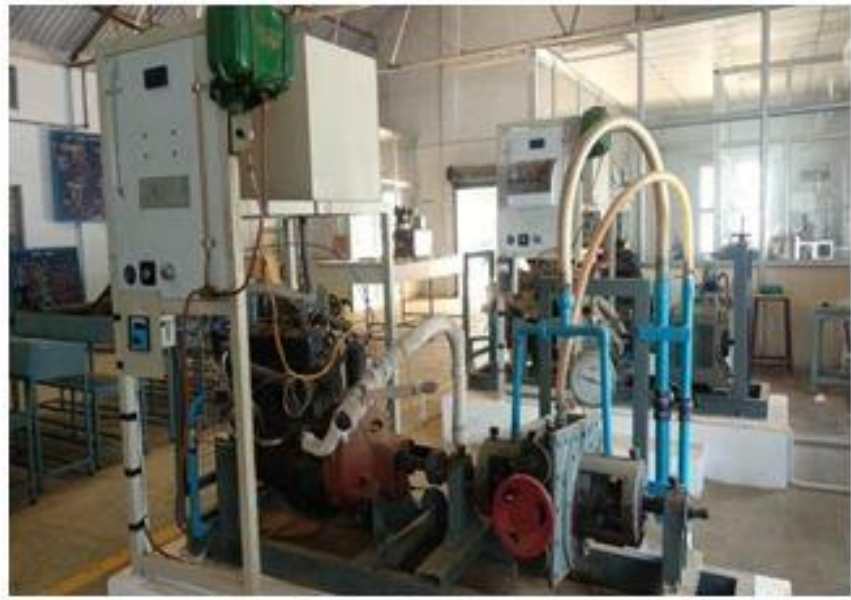

Fig. 1 Experimental Setup

A fumes gasoline analyzer or fumes $\mathrm{CO}$ analyzer is an instrument for the estimation of carbon monoxide among distinct gases within the fumes, brought approximately by using an misguided burning, the Lambda coefficient estimation is the maximum not unusual. The requirements utilized for $\mathrm{CO}$ sensors are infrared gasoline sensors (NDIR) and synthetic gasoline sensors. Carbon monoxide sensors are applied to evaluate the $\mathrm{CO}$ sum in the course of a MOT check. This will be utilized for such test it ought to be affirmed as suitable to be used inside the plan.

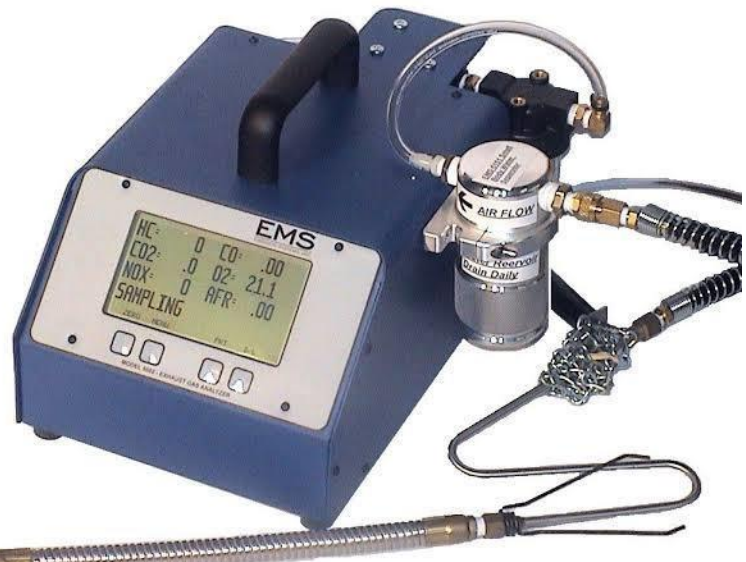

Fig. 2 Smoke Meter

Basically alcoholic content additive which contains oxygenated substance, it helps to improve for complete combustion and helps to reduce the emission which is emitted by the engine. In this process the additives can not be mixed directly to the fuel and used in the engine. They need to blended and converted into biodiesel, so here we use vegetable oil or feed stock oil to blend the diesel. In this work they blended the diesel with oil with different ratios and $10-50 \%$ of additive has been added in the fuel. These different mixtures are been tested in the multi-cylinder diesel engine. Before that neat diesel is ruined in the multi cylinder diesel engine and its rate of emission is taken and kept as a reference. Then in the second set of testing neat lemon grass oil ruined with additive mixture and the emission are been compared with the neat diesel emission. In this testing they use five gas analyzer to analyze the exhaust gas emission. This helps to measure the rate of CO2, HC, NOx, O2, and Soot. This step is fixed in the exhaust pipe so that the outlet of the engine gas is analyzed.

\section{RESULT}

The graphical representation of fig 3 represents the Specific Fuel Consumption with engine speed. This graph shows the rate of fuel consumption for pure diesel, blended bio diesel and different ratios of additives added in diesel through different color of waves. From the graph, it was absorbed that the fuel consumption rate has been increased with increasing speed. The engine has lower SFC compared to higher engine speed. In also that B30 and B40 ratio fuel consumption is constantly reduce as compared to other fuel mixtures.

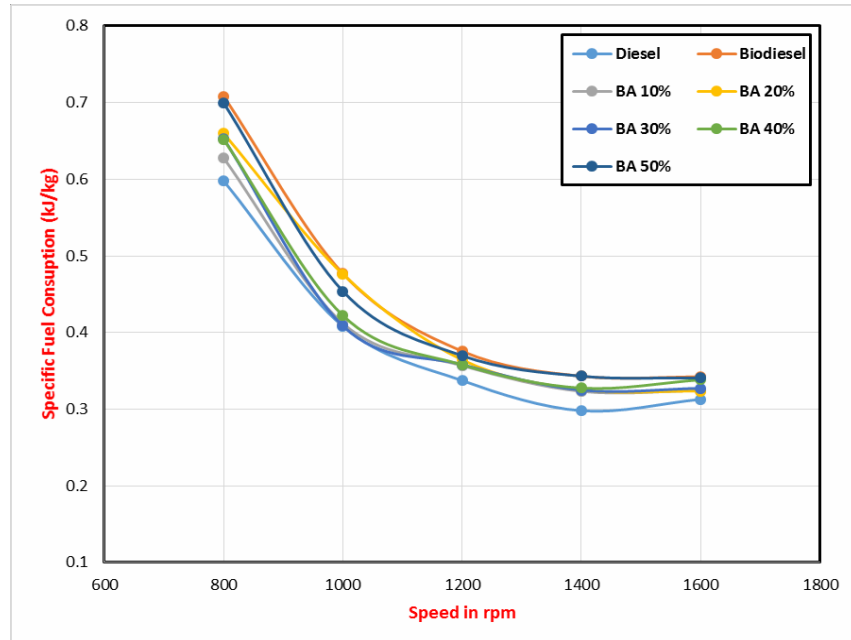

Fig.3 SFC vs Speed

The graphical representation of fig 4 represents the Brake Thermal Efficiency. This graph shows the brake thermal

\section{Fig.4 BTE vs Speed}

efficiency in pure diesel, blended bio diesel, and different ratios of additives added diesel through different color of

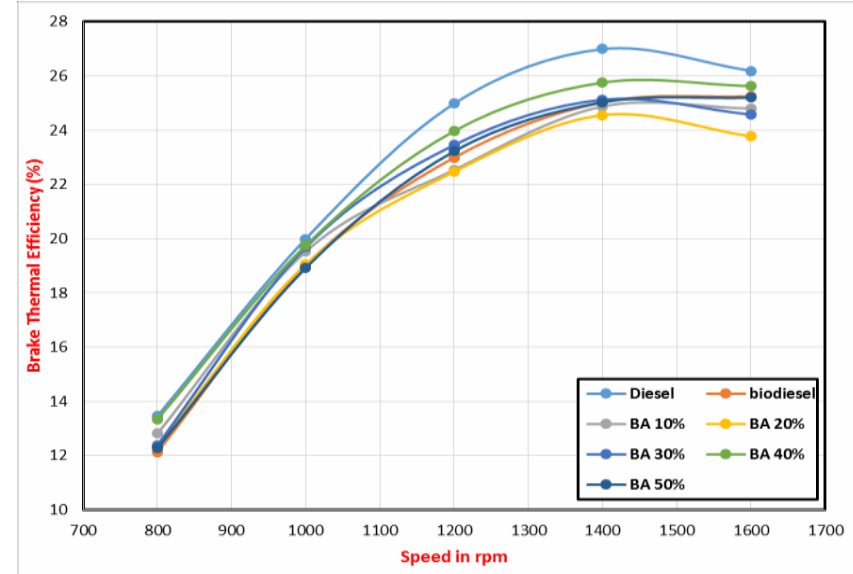

waves. In this above graph they represent that the brake thermal efficiency is lower and towards higher rpm they stars to increase. But comparing the other fuels ratio pure diesel thermal efficiency increases suddenly while rpm is increased, also that B30 and B40 ratio brake thermal efficiency is increased as lower compared to other fuel mixtures. 


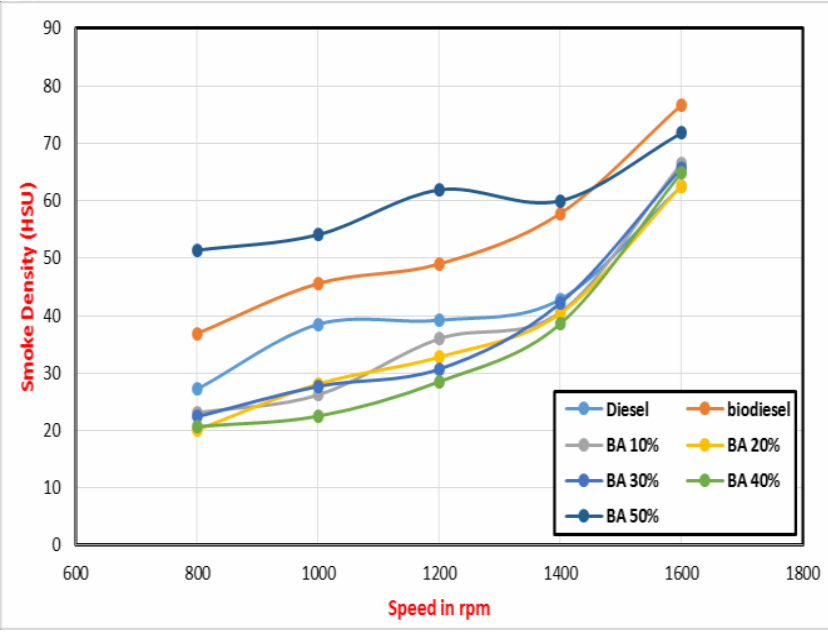

Fig.5 Smoke vs Speed

The graphical representation of fig 5 represents the Specific Fuel Consumption. This graph shows the smoke density in pure diesel, blended bio diesel, and different ratios of additives added diesel through different color of waves. In this above graph they represent that the smoke density is raised gradually for the higher rpm. Bio diesel and $\mathrm{B} 50$ ratio fuel emits higher smoke than the other fuels, also that B30 and B40 ratio smoke emission is very lower in higher rpm as compare to other fuel mixture.

The graphical representation of fig 6 represents the oxides of nitrogen. This graph shows the oxides of nitrogen in pure diesel, blended bio diesel, and different ratios of additives added diesel through different color of waves.

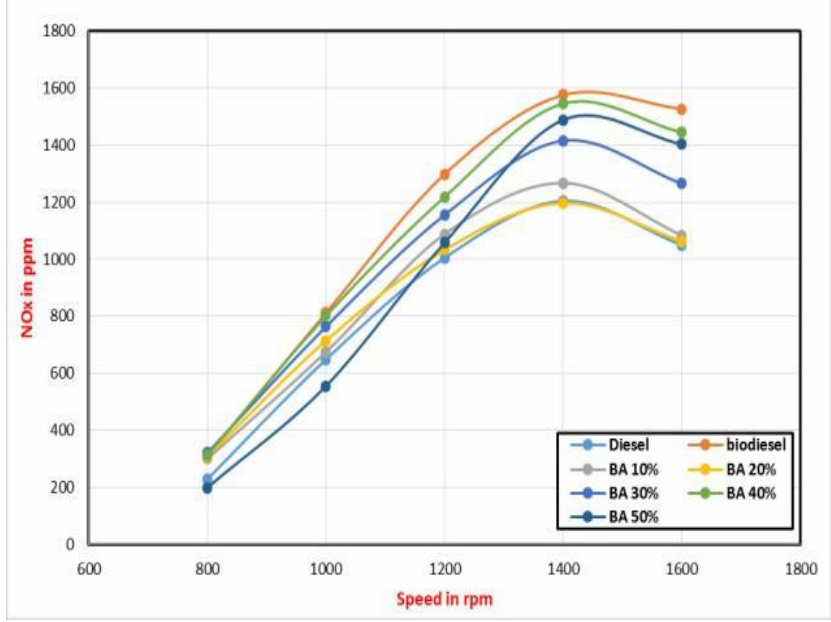

Fig.6 NOx vs Speed

In this above graph they represent that the oxides of nitrogen is raised gradually for the higher rpm. Bio diesel and B50 ratio fuel emits higher NOx than the other fuels, also that B30 and B40 ratio NOx emission is very lower in higher rpm as compare to other fuel mixture.

The graphical representation of fig 7 represents the carbon monoxide. This graph shows the carbon monoxide in pure diesel, blended bio diesel, and different ratios of additives added diesel through

different colour of waves. In this above graph they represent that the carbon monoxide is raised gradually for the higher rpm. Bio diesel and B50 ratio fuel emits higher $\mathrm{CO}$ than the other fuels, also that B30 and B40 ratio $\mathrm{CO}$ emission is very lower in higher $\mathrm{rpm}$ as compare to other fuel mixture.

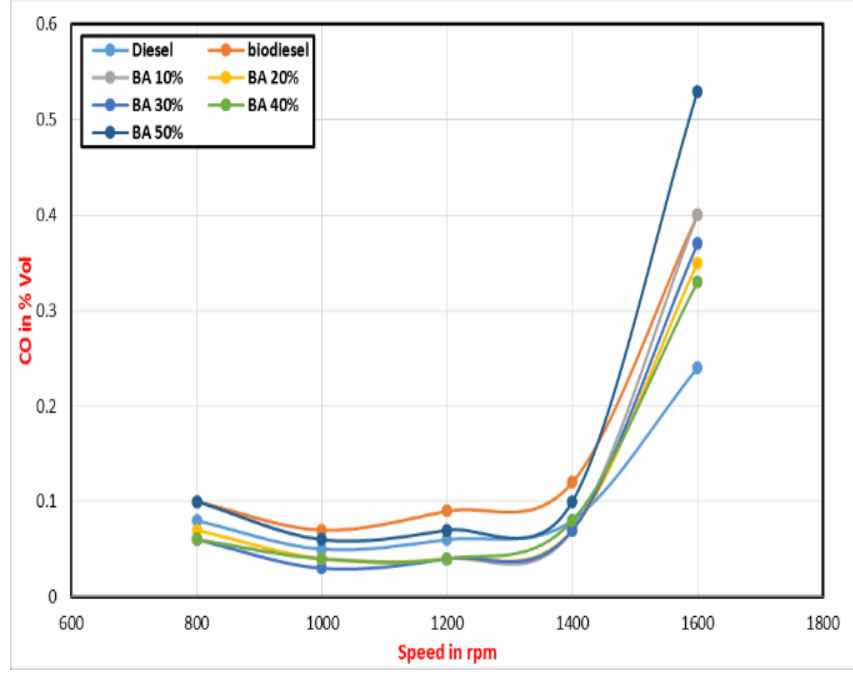

Fig.7 CO vs Speed

The graphical representation of fig 8 represents the hydrocarbon. This graph shows the hydrocarbon in pure diesel, blended bio diesel, and different ratios of additives added diesel through different color of waves.

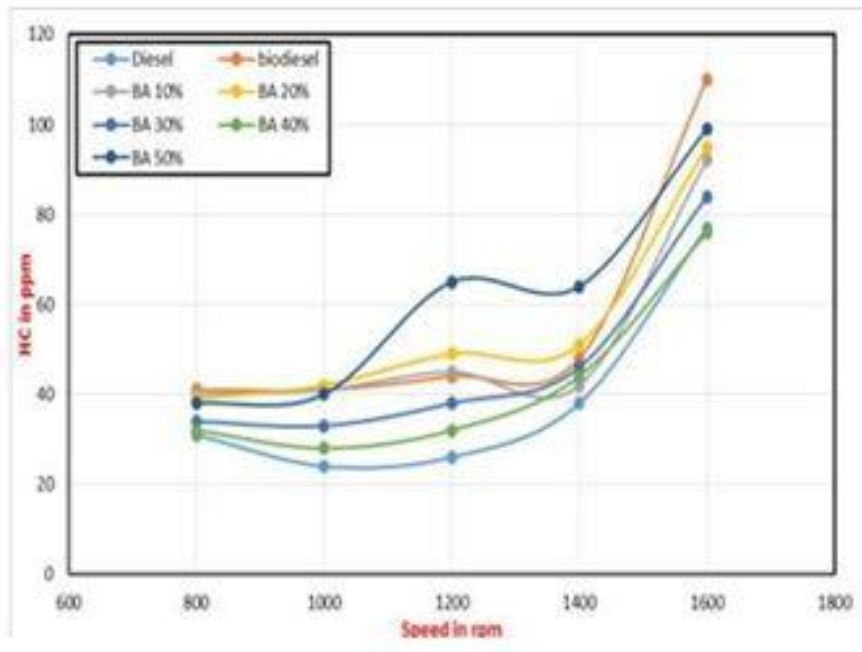

Fig. 8 HC vs Speed

In this above graph they represent that the hydrocarbon is raised gradually for the higher rpm. Bio diesel and B50 ratio fuel emits higher $\mathrm{HC}$ than the other fuels, also that B30 and $\mathrm{B} 40$ ratio $\mathrm{HC}$ emission is very lower in higher rpm as compare to other fuel mixture.

\section{CONCLUSION}

The present work, the impact of youth expansion of benzyl liquor with lemon grass oil-diesel blend on execution, discharge and ignition characteristics has been tested and contrasted

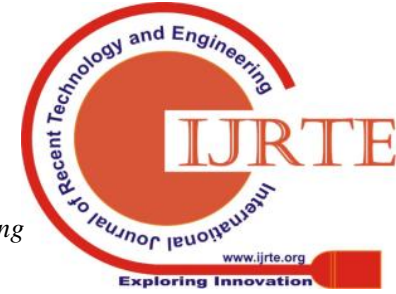


and base fuel. Benzyl alcohols had been blanketed $10 \%$, $20 \%, 30 \%, 40 \%$ and half by quantity with B30 and B40 blend. In light of the test outcomes, the accompanying ends are drawn:

- B30 and B40 decreased Brake thermal efficiency (BTE) contrasted with diesel but stepped forward it with liquor growth. Maximum BTE become seen with $10 \%$ growth of benzyl liquor with each B30 and B40.

- B30 and B40 mixes discharged less NOx outflows however higher smoke darkness. Each the alcohols supported in concurrent decrease of NO and smoke outflows. Contrasted with benzyl liquor confirmed advanced ignition prompting better NOx discharges with faded smoke.

- HC and CO emanations were better with B30 and B40 and reduced with the enlargement of liquor at higher burdens. Be that as it could, at low masses, $\mathrm{HC}$ and $\mathrm{CO}$ emanations were higher for liquor because of high inactive warmth of vaporization.

- Ignition delay for B30 and B40 was longer contrasted with diesel and broadened in addition with liquor dependence. This changed into due to dwindled cetane range for liquor.

- Significant development in pinnacle weight and warmth discharge price was cited with liquor growth, it progressed with increment in quantity of liquor.

\section{REFERENCES}

1. Hao Chen, Xin Su, Jingjing He, Bin Xie; Investigation on combustion and emission characteristics of a common rail diesel engine fueled with diesel/n-pentanol/methanol blends; Energy 167 (2019) 297-311.

2. V. Mathan Raja, L.R. GanapathySubramanianb, S. Thiyagarajanc, V. Edwin Geoc; Effects of minor addition of aliphatic (1-pentanol) and aromatic (benzyl alcohol) alcohols in SimaroubaGlauca-diesel blend fuelled CI engine; Fuels 234 (2018) 934-943.

3. AlpaslanAtmanlia, Nadir Yilmazb; A comparative analysis of $n$ butanol/diesel and 1-pentanol/diesel blends in a compression ignition engine; Fuel 234 (2018) 161-169.

4. Mingzhang Pan, Rong Huang, Jinyang Liao, Tiancheng Ouyang, Zeyuan Zheng, DelinLv,Haozhong Huang; Effect of EGR dilution on combustion, performance and emission characteristics of a diesel engine fueled with n-pentanol and 2-ethylhexyl nitrate additive; Energy and Conservation Management 176 (2018) 246-255

5. B. Coughlin, A. Hoxie; Combustion characteristics of ternary fuel Blends: Pentanol, butanol and vegetable oil; Fuels 196 (2017) 488-496.

6. Yinjie Ma, Ronghua Huang, Sheng Huang, Yu Zhang, Shijie Xu, Zhaowen Wang; Experimental investigation on the effect of n-pentanol blending on spray, ignition and combustion characteristics of waste cooking oil biodiesel; Energy and Conservation 148 (2017)440-455.

7. KeYanga,b, Long Weia, C.S. Cheunga, ChenglongTangb, ZuohuaHuangb; The effect of pentanol addition on the particulate emission characteristics of a biodiesel operated diesel engine; Fuel 209 (2017) 132-140J. Jones. (1991, May 10). Networks (2nd ed.) [Online]. Available: http://www.atm.com

8. Mohsin Raza, Longfei Chen, Rafael Ruiz, Huaqiang Chu; Influence of pentanol and dimethyl ether blending with diesel on the combustion performance and emission characteristics in a compression ignition engine under low temperature combustion mode; Journal of the Energy Institute (2019)

9. Murat KadirYesilyurt, TanzerEryilmaz, MevlütArslan; A comparative analysis of the engine performance, exhaust emissions and combustion behaviors of a compression ignition engine fuelled with biodiesel/diesel/1-butanol (C4 alcohol) and biodiesel/diesel/n-pentanol
(C5 alcohol) fuel blends; Energy (2018) EGY 13997

10. Yinjie Ma, Sheng Huang, Ronghua Huang, Yu Zhang, Shijie Xu; Ignition and combustion characteristics of n-pentanol-diesel blends in a constant volume chamber; Applied Energy 185 (2017) 519-530

11. H.K.Imdadul,H.H.Masjuki,M.A.Kalam,N.W.M.Zulkifli,AbdullahAla dulkarem,M.M.Rashed,Y.H.Teoh,H.G.How;Higher alcoholbiodiesel-diesel blends: An approach for improving the performance, emission, and combustion of a light-duty diesel engine;Energy Conversion and Management1 March (2016)174-185

12. S.Premnath, G.Devaradjane;Improving the performance and emission characteristics of a single cylinder diesel engine having reentrant combustion chamber using diesel and Jatropha methyl esters;Ecotoxicology and Environmental SafetyNovember (2015) 10

13. H.E.Saleh,Mohamed, Y.E.Selim;Improving the performance and emission characteristics of a diesel engine fueled by jojoba methyl ester-diesel-ethanol ternary blends;Fuel1 November (2017) 690-701

14. ZehraŞahin, OrhanDurgun, MustafaKurt;Experimental investigation of improving diesel combustion and engine performance by ethanol fumigation-heat release and flammability analysis;Energy Conversion and Management 1 January (2015) 175-187

15. AlpaslanAtmanli;Effects of a cetane improver on fuel properties and engine characteristics of a diesel engine fueled with the blends of diesel, hazelnut oil and higher carbon alcohol;Fuel, 15 May (2016) 209-217

16. Amrlbrahim; Investigating the effect of using diethyl ether as a fuel additive on diesel engine performance and combustion;Applied Thermal Engineering, 25 August (2016) 853-862

17. H.K.Imdadul, H.H.Masjuki, M.A.Kalam, N.W.M.Zulkifli, AbdullahAlabdulkarem, M.M.Rashed, A.M.Ashraful;Influences of ignition improver additive on ternary (diesel-biodiesel-higher alcohol) blends thermal stability and diesel engine performance;Energy Conversion and Management 1 September (2016) 252-264

18. A.K.Azad, M.G.Rasul, M.M.K.Khan, Subhash C, Sharma, M.M.K, Bhuiya;Recent development of biodiesel combustion strategies and modelling for compression ignition engines;Renewable and Sustainable Energy Reviews April (2016) 1068-1086

19. QiangZhang, NaLi, MenghanLi;Combustion and emission characteristics of an electronically-controlled common-rail dual-fuel engine; Journal of the Energy Institute November (2016) 766-781

20. MehmetÇelik, HamitSolmaz, H.SerdarYücesu;Examination of the effects of organic based manganese fuel additive on combustion and engine performance; Fuel Processing Technology,November (2015) $100-107$

\section{AUTHORS PROFILE}

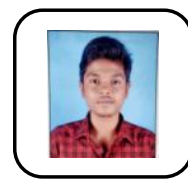

V. Saravanan, UG Student.

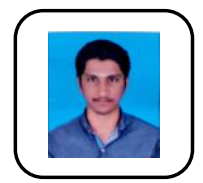

S. Nitish Kumar, UG Student

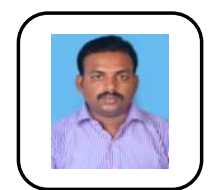

Dr. S Gowthaman, Ph.D., (IC engines), Published 11 papers in international publications, and membership in ISTE. 